ORIGINAL PAPER

\title{
COMPARISON OF THE ICC LOCATION IN THE GALLBLADDER WALL IN PATIENTS WITH CHOLELITHIASIS AND PATIENTS WITH NON-CALCULOUS CHANGES
}

\author{
Joanna Spętana, Artur Lipiński, Michae Jeleń
}

Department of Pathomorphology and Oncological Cytology, Wroclaw Medical University, Poland

\begin{abstract}
Interstitial cells of Cajal (ICC) were first described by Santiago Ramon y Cajal over 100 years ago. They are thought to play an important role in the regulation of gastrointestinal motility. There is increasing evidence that the decline in their number in the gallbladder wall contributes to the formation of concrements. The aim of the study was to determine the exact location of interstitial cells of Cajal in the gallbladder wall in patients with calculous and non-calculous cholecystitis. Sixty-eight patients were examined, of whom 50 were cases of cholelithiasis and 18 were of non-calculous cholecystitis. The technique of immunohistochemistry with the CD117 antibody was used to determine the cells of Cajal, while to distinguish them from mast cells the technique with mast cell tryptase (MCT) was applied. Redistribution of the interstitial cells of Cajal from the muscle membrane to lamina propria of mucous tissue was observed in the cases of cholelithiasis, while in the group of non-calculous cholecystitis most of the ICC was located within the muscle tissue.
\end{abstract}

Key words: ICC, interstitial cells of Cajal, distribution, gallbladder.

\section{Introduction}

The cells of Cajal (ICC - interstitial cells of Cajal) are localised in the smooth muscle layers of the gastrointestinal tract; more precisely, between the ends of autonomic neurons and muscle cells. They form connections with external neurons, just like the classical synapses. They are characterised by the ability of cyclic and spontaneous depolarisation as well as free wave formation. In such circumstances they function as a stimulator in the gastrointestinal tract $[1,2,3]$. The term is derived from the name of the Spanish neuropathologist Santiago Ramon y Cajal, who determined the spindle cells in the autonomic nerve endings in the intestines using Golgi's method $[4,5,6]$.

These cells were re-discovered approximately 40 years ago and have been successfully identified using contemporary methods, including electron micros- copy and immunohistochemistry [7]. They are described as spindle-shaped cells with a large oval nucleus embedded in a thin layer of cytoplasm and two dendritic extensions. They are characterised by the expression on their surface of proteinaceous receptors for the transmembrane tyrosine kinase (c-Kit), which allows them to be identified using the immunohistochemical technique $[5,8]$.

The presence of a large number of mitochondria, smooth sarcoplasmic reticulum, numerous lysosomes, and vacuoles in the cytoplasm of the Cajal cells has been visualised by electron microscopy $[9,10,11]$.

Numerous studies have shown that these cells are responsible for the control of gastrointestinal motility by providing electrical impulses and therefore controlling the smooth muscle contractility $[12,13]$. Any interferences in the mechanism result in many diseases, including chronic constipation, Chagas disease, Hirschsprung's disease, intestinal pseudo-obstruction, 
and congenital hypertrophic pyloric stenosis $[8,14]$. Furthermore, it is believed that the tumour cells in GIST (gastrointestinal stromal tumour) are derived from the cells of Cajal [15]. In relation to cholelithiasis and the role of ICC in the formation of concrements, it is known that reduced motility of the gallbladder wall results in cholestasis and gallstone formation $[4,7]$. Thus, the changes in the density of ICCs in the gallbladder wall may lead to the development of cholelithiasis due to the impairment of the gallbladder motility. It may be speculated that the apoptosis of cells of Cajal is the result of the chronic cholecystitis [16].

The aim of the study was to compare the location of ICC in the gallbladder wall in patients with cholelithiasis and patients with non-calculous changes of this organ.

\section{Material and methods}

The research material consisted of gallbladder tissue sections removed during cholecystectomy in the University Clinical Hospital of J. MikuliczRadecki in Wroclaw. Patients, before their surgery, were informed about the possibility of using their tissue for scientific research or for didactic purposes carried out at the Medical University of Wroclaw. The sections were fixed, embedded in paraffin beforehand, examined by pathologists, and archived in the Department of Pathomorphology and Oncological Cytology of the Medical University in Wroclaw.

The archival microscopic preparations of gallbladder tissue were subjected to retrospective consultation assessment. Representative, well-preserved specimens were chosen for immunohistochemistry and were selected for the study.

The material, including 68 sections of the gallbladder, was divided into two groups according to the histopathological diagnosis. The group with a diagnosis of chronic cholelithiasis consisted of 50 cases (40 women and 10 men). The group with non-calculous gallbladder diseases (chronic cholecystitis, acute cholecystitis, gallbladder empyema) consisted of 18 cases (12 women and 6 men).

\section{Immunohistochemistry}

Immunohistochemical staining was performed automatically using the Autostainer Link 48 apparatus (Dako-Agilent). Sections were deparaffinised in xylene and a variety of decreasing concentration alcohols, and subsequently antigens were detected in Target Retrieval Solution (Dako-Agilent) by being heated at $96^{\circ} \mathrm{C}$ for $20 \mathrm{~min}$. The endogenous peroxidase was blocked by incubating the sections with $3 \% \mathrm{H}_{2} \mathrm{O}_{2}$ for $10 \mathrm{~min}$. Primary antibodies were used, including Polyclonal Rabbit Anti-Human CD117 (c-kit, Cat. No. A4502, Dako-Agilent) and FLEX Monoclonal Mouse Anti-Human Mast Cell Tryptase Klon AA1 (RTU Cat. No. IS 640, Dako-Agilent). En Vision FLEX High pH and EnVision G/2 System/ AP (Permanent Red) visualisation sets were used to enhance the reactions.

Histopathological specimens were evaluated using an optical microscope (Olympus BX 51); the number of Cajal cells was counted by researchers in the next 20 high-power fields (magnification $400 \times$ ) with a positive IHC reaction and then converted into an area of $1 \mathrm{~mm}^{2}$ of the preparation, using the dotSlide program function. The results for individual cases were recorded in a Microsoft Excel spreadsheet. The microscope images were taken using an Olympus digital camera (U-CMAD3) and dotSlide software and archived in .jpg format on the computer's hard drive.

\section{Statistical methods}

Statistical analysis was performed using Statistica 12 (StatSoft Poland). The first stage was to test the normality distribution for variables (the Shapiro-Wilk test, significance level $\mathrm{p}=0.05$ ). Due to an unequal number of test groups and the deviations from normal distribution, the Mann-Whitney $U$ test (significance level $p=0.05$ ) was applied in the subsequent statistical analysis. The test showed statistically significant differences in the location of cells of Cajal in both groups.

\section{Results}

ICC were defined as CD-117-positive cells (membrane/cytoplasmic reaction) of an elongated shape as opposed to the round and larger mast cells, which were shown both by CD-117 and MCT expressions (cytoplasmic reaction). In patients with diagnosed cholelithiasis, the cells of Cajal were positioned individually, in parallel to the muscle fibres, in most cases, between the smooth muscle layer and the lamina propria of the gallbladder wall (Figs. 1, 2).

In patients with the diagnosed non-calculous cholecystitis the cells of Cajal were located mostly within the muscle membrane of the gallbladder wall (Fig. 3). They occurred more frequently in groups of three or four cells (Fig. 4).

In general, a greater number of cells of Cajal were observed per $1 \mathrm{~mm}^{2}$ of the tissue in patients with non-calculous cholecystitis than in the group of patients with calculous cholecystitis. The average number of cells of Cajal in individual parts of the gallbladder wall (per $1 \mathrm{~mm}^{2}$ of the preparation) is shown in Table I. 




Fig. 1. Preparation of the gallbladder in patients with calculous cholecystitis; CD 117 (red) and the mast cell tryptase (brown); A) the cell of Cajal located between the smooth muscle layer and lamina propria, B) mast cell; $400 \times$ magnification

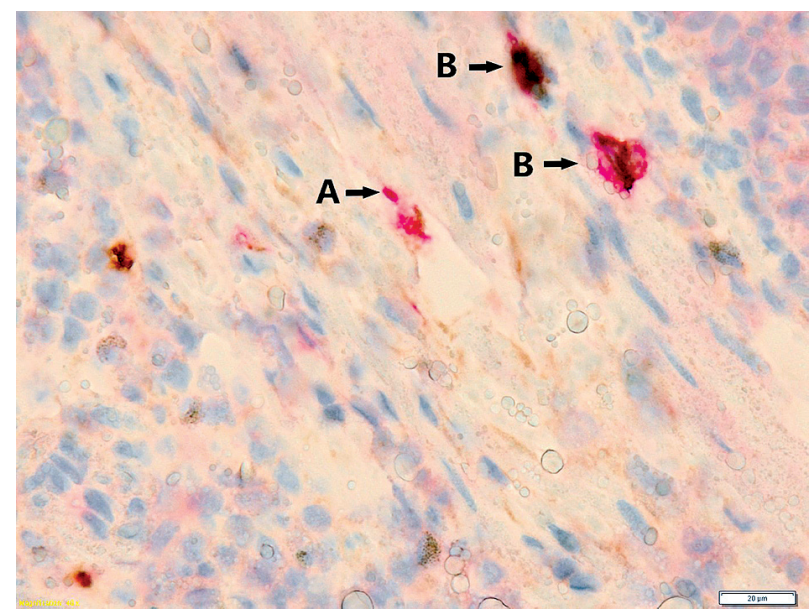

Fig. 3. Preparation of the gallbladder in patients with non-calculous cholecystitis; CD 117 (red) and the mast cell tryptase (brown); (A) the cell of Cajal located in the smooth muscle layer, (B) mast cell; $400 \times$ magnification

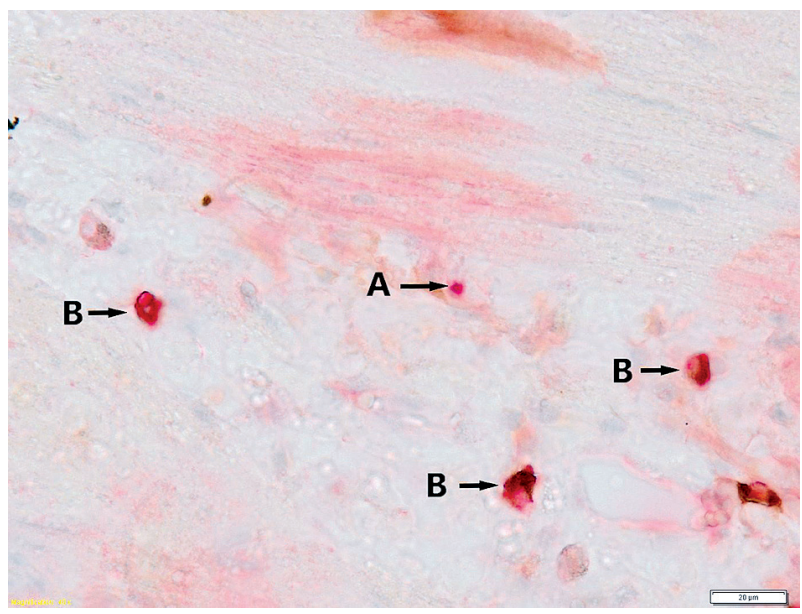

Fig. 2. Preparation of the gallbladder in patients with calculous cholecystitis; CD 117 (red) and the mast cell tryptase (brown); A) the cell of Cajal located in lamina propria, B) mast cell; $400 \times$ magnification

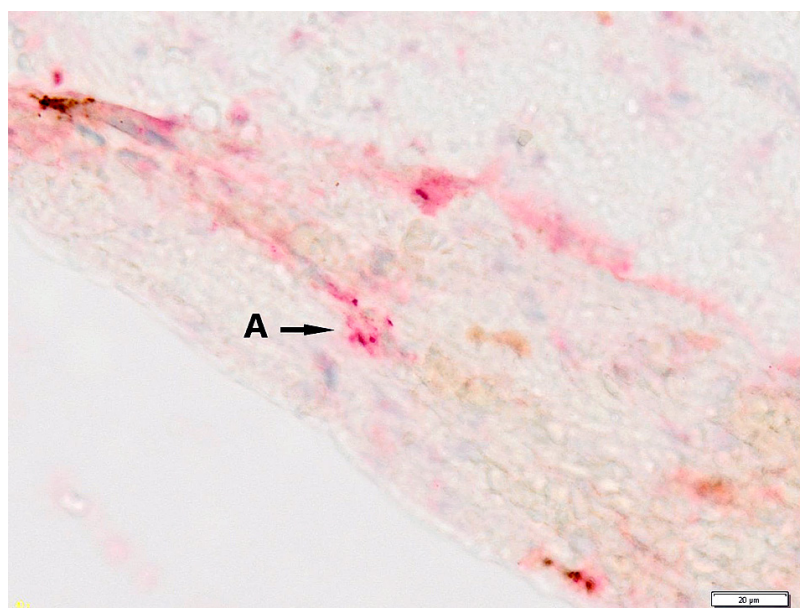

Fig. 4. Preparation of the gallbladder in patients with non-calculous cholecystitis; CD 117 (red) and the mast cell tryptase (brown); (A) a group of cells of Cajal; $400 \times$ magnification

Table I. Mean number of ICCs in the different layers of the gallbladder wall

\begin{tabular}{|c|c|c|}
\hline \multirow[t]{2}{*}{ LOCALIZATION OF ICCs } & \multicolumn{2}{|c|}{ MeAn Number of ICCs IN 1 MM$^{2}$ TISSUe } \\
\hline & Calculous CHOlecystis & Non-CAlCUlOUS CHOLECYSTIS \\
\hline Muscular layer & 12.91 & 31.22 \\
\hline Mucosa & 25.55 & 18.63 \\
\hline Total & 38.46 & 49.85 \\
\hline
\end{tabular}

\section{Discussion}

This study compared the location of cells of Cajal in the gallbladder wall in patients with diagnosed calculous cholecystitis and acalculous cholecystitis.
Redistribution of the cells of Cajal from the muscle layer to the submucosa layer in the course of cholelithiasis has been observed. Studies suggest that the cells of Cajal in the course of cholecystitis accompanied by cholelithiasis are subject to apopto- 
sis in the smooth muscle layer or they are relocated to the lamina propria. The location of ICC, between the two aforementioned layers of the gallbladder wall, adjacent to the smooth muscles, is of great importance. The experiment on the apoptosis of ICC, performed on the material taken from the patients' intestines, was carried out by Gibbons et al. (2009). By using the apoptosis markers (amongst others, Caspasa-3), the study identified apoptotic ICC in the normal human colon. The discovery of apoptotic ICC in normal tissue puts forward the hypothesis that continuous supplementation of ICC is required to maintain a network of such cells and therefore normal gastrointestinal motility. In this regard, a slight change in balance between death and supplementing leads to a premature loss of ICC, which contributes to the development of gastrointestinal motility disorders [17].

In patients with non-calculous cholecystitis, the cells of Cajal are concentrated in small groups, which may suggest that they are able to create connections between each other and to form ICC networks $[9,18]$.

Gastrointestinal motility is controlled by several integrated systems, including neurogenic, myogenic, and endocrine, as well as the interstitial cells of Cajal. This complex regulation is disturbed in the inflammatory processes, which is reflected in the reports on motility disorders in inflammatory bowel diseases (IBD) and animal models of IBD. According to the reports of Galeazzi [19], who, using a animal model, evaluated the effect of inflammation on the intestine physiology, it changes the nerve-muscle activity through complex mechanisms, dependent, amongst others, on macrophages and myeloperoxidase activity. Our research shows that the cells of Cajal are subject to some changes in the course of inflammation. Above all, these cells relocate in the gallbladder wall during the inflammatory process of cholelithiasis, which may not be observed in cholecystitis, which in turn is not accompanied by cholelithiasis.

Numerous studies have established the existence of correlation between the reduced number of ICCs in gastrointestinal diseases and abnormal gastrointestinal motility $[20,21]$. It has been found that the reduced amount of ICC in the gallbladder wall contributes to irregularities in emptying the gallbladder and consequently in forming concrements [4, 16, 22].

Moreover, cholecystitis in the course of cholelithiasis additionally increases dysfunctions in the contractility of this organ. Similar conclusions reported earlier by Suzuki et al. [23], in an animal model infected with Trichinella spiralis, have shown that the inflammation of mucous tissue of the gastrointestinal tract organs may weaken the motility of intestines by strengthening inflammatory reactions within the muscle layers. This may cause changes in intestinal functions and lead to systemic diseases in advanced cases. Acute and chronic cholecystitis in the context of cellular immune response was considered by Kasprzak et al. [24]. Their study was to research the quantitative analysis of expressions with the markers of mast cells (tryptase), monocytes / macrophages (CD68 molecule) and dendritic cells (protein S100) in mucous tissue of the gallbladder in patients with acute and chronic cholecystitis. Various essential functions of the tested cell types in nonspecific immunological response, which accompanies the calculous cholecystitis, have been found. This may have a significant impact on the change of ICC location within the gallbladder wall.

The study of Hinescu et al. [25] was one of the first reports on the issue of ICC in human gallbladder wall. The density and location of ICC in the gallbladder wall was described on the basis of immunohistochemical tests of fresh tissue sections. His calculations showed that the ICC density was $100-110$ cells $/ \mathrm{mm}^{2}$, and the described cells were positioned in lamina propria, slightly closer to the epithelial tissue, in spaces of connective tissue, between the bundles of smooth muscle cells and the muscle layer of the wall. Our observations confirm the location of the cells of Cajal in the gallbladder wall. As reported previously, in patients with cholelithiasis, the cells of Cajal occurred in greater numbers in lamina propria than in the muscle layer itself.

Research performed by Pasternak et al. [7] proved to be of great value, showing a significant decrease in the ICC density in the gallbladder wall in patients with cholelithiasis. Their aim was to compare the location and number of ICCs in the gallbladder wall in patients with cholelithiasis and in patients without gallstones. As for the ICC location, the cells of Cajal were almost exclusively observed within the muscularis proper, lying parallel to the smooth muscle cells. However, in some cases, ICCs were located in the connective tissue, which separates the smooth muscle bundles. Thus, despite slight differences in observations, the location of ICC in cases of cholelithiasis, described by us, was also observed in their test group.

To conclude, the performed studies clearly confirm that a reduced number of the cells of Cajal as well as their reorganisation in the gallbladder wall contribute to abnormal motility of this organ. This is mainly connected with the bile discharge issue, which subsequently leads to cholestasis and formation of concrements. The whole pathology is undoubtedly associated with the incidence of calculous cholecystitis.

This research was financed through a statutory subsidy by the Polish Minister of Science and Higher Education as 
a part of grant ST.B130.18.030 (record numbers in the Simple system).

The authors declare no conflict of interest.

\section{References}

1. Pasternak A, Szura M, Gil K, et al. Interstitial cells of Cajal systematic review. Folia Morphol 2016; 75: 281-286.

2. Baker SA, Drumm BT, Skowronek KE, et al. Excitatory Neuronal Responses of Ca 2+ Transients in Interstitial Cells of Cajal in the Small Intestine. Eneuro 2018; 5; 1-22.

3. Lavoie B, Balemba OB, Nelson MT, et al. Morphological and physiological evidence for interstitial cell of Cajal-like cells in the guinea pig gallbladder. J Physiol 2007; 579: 487-501.

4. Fan Y, Wu S, Fu B, et al. The role of interstitial Cajal-like cells in the formation of cholesterol stones in guinea pig gallbladder. Hepatol Int 2015; 9: 612-620.

5. Ahmadi O, de L Nicholson M, Gould ML, et al. Interstitial cells of Cajal are present in human extrahepatic bile ducts. J Gastroenterol Hepatol 2010; 25: 277-285.

6. Popescu LM, Ciontea SM, Cretoiu D, et al. Interstitial Cajallike cells in human uterus and fallopian tube. Ann N Y Acad. Sci 2007; 1101: 139-165.

7. Pasternak A, Gil K, Matyja A, et al. Loss of gallbladder interstitial Cajal-like cells in patients with cholelithiasis. Neurogastroenterol Motil 2013; 25: 17-24

8. Pilecki W, Koleda P, Nature of Interstitial Cells of Cajal of the Upper Urinary Tract. Adv Clin Exp Med 2014; 23: 627-632.

9. Iino S, Horiguchi K, Interstitial Cells of Cajal Are Involved in Neurotransmission in the Gastrointestinal Tract. Acta Histochem Cytochem 2006; 39: 145-153.

10. Hanani M, Farrugia G, Komuro T, et al. Intercellular coupling of interstitial cells of cajal in the digestive tract. Int Rev Cytol 2004; 242: 249-282.

11. Xu D, Yu BP, Luo HS, et al. Control of gallbladder contractions by cholecystokinin through cholecystokinin-A receptors on gallbladder interstitial cells of cajal. World J Gastroenterol 2008; 14: 2882-2887.

12. Beckett EAH, Horiguchi K, Khoyi M, et al. Loss of enteric motor neurotransmission in the gastric fundus of Sl/Sldmice. J Physiol 2002; 543: 871-887.

13. Pasternak A, Szura M, Mazur M, et al. Number and Distribution of Interstitial Cells of Cajal in Human Gallbladder. Folia Med Cracov 2014; 1: 71-77.

14. Apoznanski W, Koleda P, Wozniak Z, et al. The distribution of interstitial cells of Cajal in congenital ureteropelvic junction obstruction. Int Urol Nephrol 2013; 45: 607-612.

15. Mendoza-Marin M, Hoang MP, Albores-Saavedra J, et al. Malignant stromal tumor of the gallbladder with interstitial cells of Cajal phenotype. Arch Pathol Lab Med 2002; 126: 481-483.

16. Portincasa P, Di Ciaula A, Vendemiale, et al. Gallbladder motility and cholesterol crystallization in bile from patients with pigment and cholesterol gallstones. Eur J Clin Invest 2000; 30: 317-324.

17. Gibbons SJ, De Giorgio R, Faussone Pellegrini MS, et al. Apoptotic cell death of human interstitial cells of Cajal. Neurogastroenterol Motil 2009; 21: 85-93.

18. Iino S, Horiguchi S, Horiguchi K, et al. Interstitial cells of Cajal in the gastrointestinal musculature of $\mathrm{W}$ jic c-kit mutant mice. J Smooth Muscle Res 2011; 47: 111-121.

19. Galeazzi F, Haapala EM, van Rooijen N, et al. Inflammation-induced impairment of enteric nerve function in nematode-infected mice is macrophage dependent. Am J Physiol Gastrointest Liver Physiol 2000; 278: G259-G265.

20. Negreanu LM, Assor P, Mateescu B, et al. Interstitial cells of Cajal in the gut - A gastroenterologist's point of view. World J Gastroenterol 2008; 14: 6285-6288.
21. Forster J, Damjanov I, Lin Z, et al. Absence of the interstitial cells of Cajal in patients with gastroparesis and correlation with clinical findings. J Gastrointest Surg 2005; 9: 102-108.

22. Pasternak A, Gajda M, Gil K, et al. Evidence of interstitial Cajal-like cells in human gallbladder. Folia Histochem Cytobiol 2012; 50: 581-585.

23. Suzuki T, Kyung-Jong W, Horiguchi K, et al. Muscularis inflammation and the loss of interstitial cells of Cajal in the endothelin ETB receptor null rat. AJP Gastrointest Liver Physiol 2004; 287: G638-G646.

24. Kasprzak AA, Szmyt M, Malkowski W, et al. Expression of phenotypic markers of mast cells, macrophages and dendritic cells in gallbladder mucosa with calculous cholecystitis. Polish J Pathol 2013; 64: 281-289.

25. Hinescu ME, Ardeleanu C, Gherghiceanu M, et al. Interstitial Cajal-like cells in human gallbladder. J Mol Histol 2007; 38: 275-284.

\section{Address for correspondence}

\section{Joanna Spętana}

Department of Pathomorphology and Oncological Cytology

Wroclaw Medical University

ul. Borowska 213

50-556 Wroclaw, Poland

e-mail: jspetana@outlook.com 